Gut, 1961, 2, 150

\title{
Some metabolic and haematological effects of oesophago-jejunostomy with by-pass of the stomach
}

\author{
Sheila T. CAllender, L. J. Witts, P. R. Allison, AND A. GUNNing \\ From the Nuffield Departments of Clinical Medicine and of Surgery, \\ the Radcliffe Infirmary, Oxford
}

SYNOPSIS Twelve subjects have been studied in whom oesophago-jejunostomy had been performed leaving the stomach in situ. All had considerable metabolic disturbance with steatorrhoea and inability to absorb vitamin $B_{12}$, and the operation has been abandoned in favour of oesophagojejuno-gastrostomy.

The need for a radical total gastrectomy for carcinoma of the upper part of the stomach led to the use of the Roux loop of jejunum for restoring intestinal continuity. The nature of the disease, and the pressing indication for removal, forced the hand of the surgeon to leave his patient in what would appear to be a most undesirable physiological state, where the food passed straight from the oesophagus into the small intestine, meeting the bile and pancreatic juice 10 or 12 in. below the anastomosis where a $\mathrm{T}$ junction was made between the loop and the duodeno-jejunal flexure (Fig. 1a).

Many of the patients with total gastrectomy led a surprisingly normal life, eating well, though not gaining weight, having a single bowel action a day, and earning their living. If they lived long enough, however, they all developed a megaloblastic anaemia unless they were treated prophylactically with vitamin $\mathrm{B}_{\mathbf{1 2}}$.

The success of oesophago-jejunostomy in these patients led to the adoption of a similar operation for people with severe peptic stricture of the oesophagus. In them, however, there was no necessity to remove the stomach. The need was to remove the stricture and to prevent the digestive juices of the stomach from reaching the oesophageal mucosa which was ill prepared to withstand its corrosive action. The patients were mainly adults and in the same age group as those suffering from carcinoma. It seemed reasonable, therefore, to excise the oesophageal stricture, to close the cardiac end of the stomach completely and to join the oesophagus to a Roux loop of jejunum. In this way the food passed from oesophagus to jejunum without ever entering the stomach. The gastric juice could not enter the oesophagus, and whatever might be secreted would join the bile and pancreatic juice to enter the jejunum and mix with the food at the T anastomosis (Fig. 1b). When the stomach thus became a rather distant cul-de-sac of the alimentary canal it was not possible to determine whether it did in fact continue to secrete normally. This operation was only performed on middle-aged and elderly adults and was never applied to the problem of peptic stricture in young children. It was the use of an isolated loop of jejunum to replace the resected stricture in children (Fig. 1c) that led to the abandoning of the operation described above for adults; but in the meantime a small series of patients had become available for metabolic study which was unique and unlikely to occur again.

In all the operation was performed 40 times. Six of the patients succumbed within six months, two of them from uncontrollable pulmonary tuberculosis. Thirty-four remaining patients gave a general clinical post-operative picture which varied with the condition before operation. Some who were emaciated from prolonged starvation gained weight rapidly, one man increasing from $84 \mathrm{lb}$. to $154 \mathrm{lb}$. in about a year, subsequently falling to a steady $127 \mathrm{lb}$. None ever regained the weight that had been normal before oesophageal stenosis occurred. The men made an outstandingly better metabolic recovery than the women. All had looseness of the bowels, particularly after meals, for periods varying from one to six months, and while many returned to a single formed stool a day, most were subject to attacks lasting one to three days in which they would have three to five 


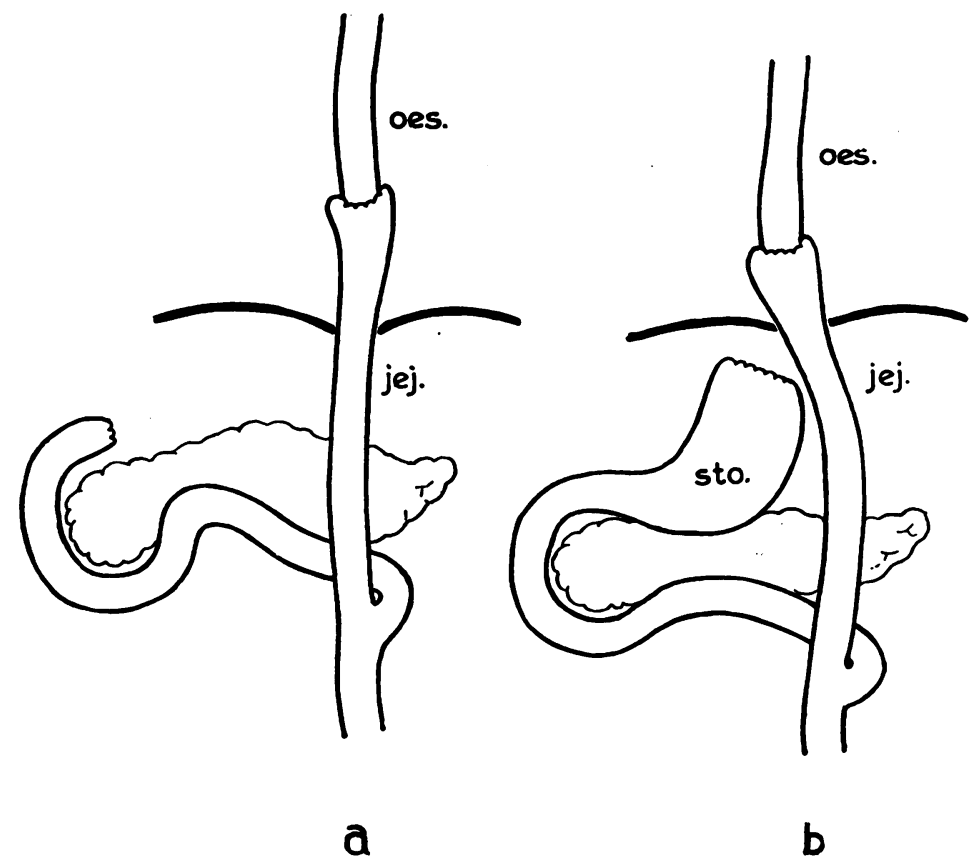

FIG. 1. a oesophago-jejunostomy with total gastrectomy, b oesophago-jejunostomy with by-pass of the stomach, c oesophago-jejuno-gastrostomy.

bowel actions. Practically all had a tendency to feel faint with an increased pulse rate after meals. This was most marked and lasted longer in the women than in the men. This symptom became less with time and was diminished by eating small dry meals and drinking between meals. After a short time some of the men declared that they ate normal meals with the rest of the family and had no discomfort whatever; many of the women continued to rest for half an hour after meals.

One of the most interesting post-operative features was the development of anaemia in several of the subjects. It was primarily to investigate this aspect of the condition that the present study was undertaken.

\section{MATERIAL}

All the surviving patients were asked if they would come into hospital for a period for investigation. They had all been operated on in Leeds and this meant their coming to Oxford. Twelve agreed to come. There was a natural tendency for those with troublesome post-operative symptoms to be prepared to come; there was also a preponderance of women in the sample.

This group of 12 who had been subjected to the operation of oesophago-jejunostomy with by-pass of the stomach was compared with two patients who had had an oesophago-jejuno-gastrostomy. Three of the 12 patients were sufficiently disabled to agree to having the oesophago-jejunostomy converted to an oesophago-jejuno-gastrostomy and further observations were made on these three (A.B., E.D., and G.W.) after re-operation.

\section{METHODS}

As many as possible of the following investigations were carried out on each subject:-

1 A venous blood sample was taken and the blood count, prothrombin, serum iron, blood urea, serum calcium, phosphate and phosphatase, and the total and albumin fractions of the plasma proteins were estimated. Blood films and sternal marrow were examined.

2 SERUM VITAMIN $B_{12}$ Serum vitamin $B_{12}$ was estimated by microbiological assay with Lactobacillus leichmannii as the test organism (Spray, 1955). Using this method Spray found that the majority of patients with pernicious anaemia have values below $100 \mu \mu \mathrm{g} . / \mathrm{ml}$.; the mean in 92 such patients was $64 \mu \mu \mathrm{g} . / \mathrm{ml}$. In control subjects values obtained lay between 150 and $1,000 \mu \mu \mathrm{g}$./ml. with a mean of $450 \mu \mu \mathrm{g} . / \mathrm{ml}$. (Spray and Witts, 1958).

3 THE ABSORPTION OF VITAMIN $B_{12}$ Vitamin $B_{12}$ labelled with radioactive cobalt was used to study absorption of the vitamin. A dose of $0.5 \mu \mathrm{g}$. was given to the fasting 
subject in about $30 \mathrm{ml}$. of water. Nothing more was given to eat or drink for a further two hours. The subjects were provided with waxed cardboard containers in which to collect all stools which were passed subsequently and the collections were continued until less than $1 \%$ of the dose given was found in two successive specimens. Radioactivity was measured in a double ring of 32 Geiger-Müller tubes (Bradley, 1957). It was assumed that all the activity recovered in the faeces represented the proportion of the dose which was not absorbed and from this the percentage absorption of the labelled vitamin was calculated. In all those who showed abnormal absorption of vitamin $B_{12}$ the test was repeated with the addition of $50 \mathrm{mg}$. of an active preparation of intrinsic factor (Lederle, 45774-133).

Using this faecal technique we have found that control subjects excrete 14 to $45 \%$ of the oral dose (mean $31 \%$ ) and patients with pernicious anaemia 64 to $100 \%$ (mean $88 \%$ ) (Callender, Turnbull, and Wakisaka, 1954; Retief, 1959), i.e., control subjects absorb 55 to $86 \%$ of the $0 \cdot 5-\mu \mathrm{g}$. dose and patients with pernicious anaemia 0 to $36 \%$. The addition of $50 \mathrm{mg}$. of Lederle 45774-133 preparation of intrinsic factor reduced the excretion in patients with pernicious anaemia to 32 to $57 \%$ (mean $47 \%$ ) (unpublished observations).

In some subjects a further test of absorption of vitamin $B_{12}$ was made, $0.25 \mathrm{mg}$. of carbachol being given half an hour before the labelled vitamin. In others $0.04 \mathrm{mg}$. per kg. body weight of histamine acid phosphate was given subcutaneously half an hour after an intramuscular injection of mepyramine maleate (Anthisan) and the dose of labelled vitamin was given half an hour after the histamine injection. With both these procedures it could be expected that there would be an outpouring of gastric secretion which would reach a maximum about 15 minutes after the carbachol or histamine and be maintained for about $\mathbf{3 0}$ minutes.

In interpreting the effect of various factors on absorption of labelled vitamin $B_{12}$ the variability of the test should be considered. In 10 reliable subjects who carried out duplicate tests within a short interval of time the results varied by 0 to $9 \%$ of the oral dose (mean $4 \%$, S.D. $3 \%$ ). Taking the 94 subjects who have had duplicate tests, under apparently similar conditions, since the introduction of the test in our department, the difference was as much as 0 to $22 \%$ (mean $7 \%$, S.D. $6 \%$ ) (Deller, Germor, and Witts, 1961). The latter figures include patients who had tests at intervals of several months or even years and may include some who were unreliable in collecting stools although they all denied this source of error.

4 IRON ABSORPTION This was studied by measuring the proportion of an oral dose of ferrous sulphate, containing $5 \mathrm{mg}$. ${ }^{59} \mathrm{Fe}$, which was recovered in the faeces. The faeces were homogenized, weighed samples were counted in a scintillation counter and the counts compared with a standard prepared from an aliquot of the original solution given. The proportion not recovered was assumed to have been absorbed. The proportion of the dose which was incorporated in the red cells was also measured. Using this method control subjects absorbed
11 to $68 \%$ of the $5 \mathrm{mg}$. dose of iron (mean $25 \%$ ) and subjects with iron deficiency 24 to $96 \%$ (mean $58 \%$ ) (Callender, Mallett, and Smith, 1957).

5 UROPEPSINOGEN This was estimated in a 24-hour sample of urine by a modification of the method of Anson (1938). Using this technique, Aitken, Spray, and Walters (1954) found that control subjects excreted 60 to 250 units per 24 hours (mean 136 units) and patients with pernicious anaemia 0 to 55 units (mean 19 units).

6 XYLOSE ABSORPTION The absorption of d-xylose was measured indirectly by estimating the proportion of an oral dose of $25 \mathrm{~g}$. of xylose which was excreted in the urine over a five-hour period. The dose was given in the morning, in $500 \mathrm{ml}$. of water, with the patient fasting. The method of assay was by paper chromatography (Perry, 1960). Using this method control subjects were found to excrete 3.2 to $9.2 \mathrm{~g}$. in the five-hour period (mean 6.2).

7 FAECAL FAT This was estimated by the method of van de Kamer, ten Bokkel Huinink, and Weyers (1949) on four-day collections of faeces with a dietary intake of approximately $70 \mathrm{~g}$. of fat daily. The upper limit of normal was taken as $6 \mathrm{~g}$. per day.

8 FAECAL NITROGEN This was estimated by Kjeldahl digestion on the same four-day collections of faeces. The upper limit of normal was taken as $\mathbf{2} \mathbf{g}$. per day.

9 BIOPSIES Gastric and jejunal biopsies were taken either under direct vision through an oesophagoscope or at the time of re-operation.

RESULTS IN PATIENTS WITH OESOPHAGO-JEJUNOSTOMY AND BY-PASSED STOMACH

GENERAL OBSERVATIONS Most of the 12 patients had lost weight since operation and the three who had gained some weight were still considerably undernourished. In all but two diarrhoea had been a troublesome feature, especially in the first year or more after operation. In three the diarrhoea had completely disappeared and one was even constipated. The remainder had one to three soft stools a day with occasionally rather more looseness of the bowels. It was noteworthy that when adequate treatment with vitamin $\mathbf{B}_{12}$ was instituted the diarrhoea was greatly improved, e.g., V.T. had distressing bouts of diarrhoea with six to seven bowel actions every 24 hours, often being disturbed through the night. After starting treatment with vitamin $\mathbf{B}_{12}$ she had only one or two actions a day, the stools being normal in consistency.

They had all been directed to take Hepamino (a proteolysed liver preparation) after operation and they all did so in doses varying from one teaspoonful to three dessertspoonfuls daily. In spite of this, five 
TABLE I

DATA IN 12 SUBJECTS WITH OESOPHAGO-JEJUNOSTOMY AND BY-PASS OF THE STOMACH AND TWO WITH OESOPHAGO-JEJUNO-GASTROSTOMY

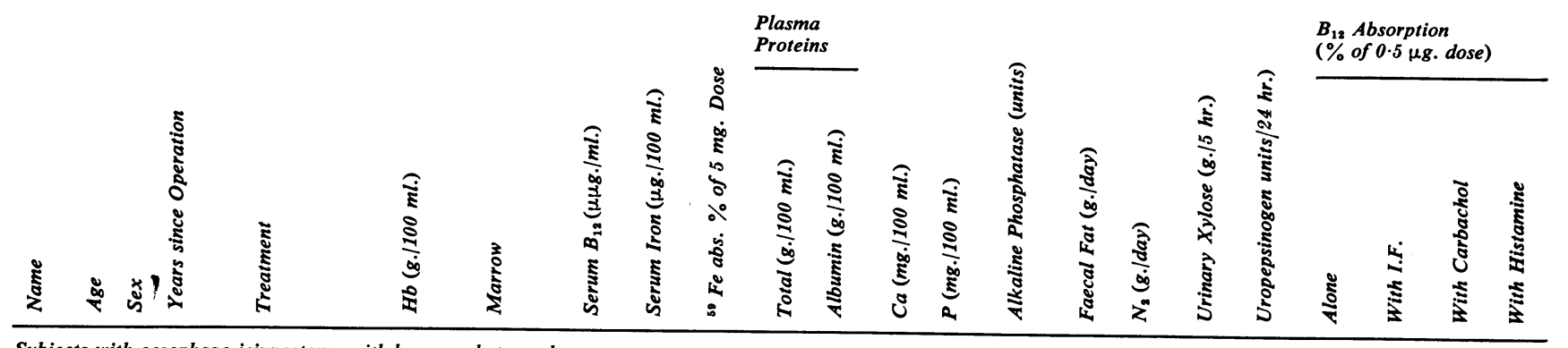

Subjects with oesophago-jejunostomy with by-passed stomach

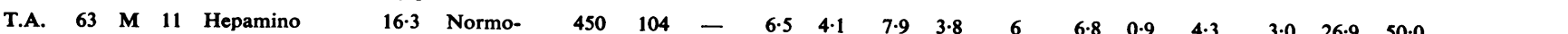

$\begin{array}{llllllllllllllllllllll}\text { Normo- } & 450 & 104 & - & 6.5 & 4.1 & 7.9 & 3.8 & 6 & 6.8 & 0.9 & 4.3 & 3.0 & 26.9 & 50.0 & - & - & - & \end{array}$

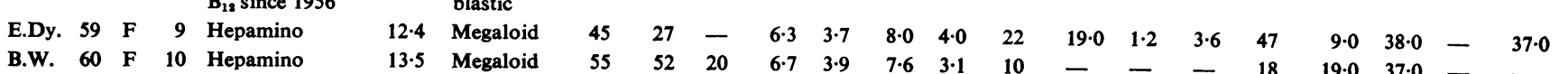

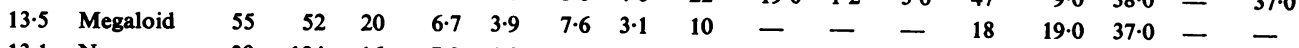

D.C. ${ }^{1} 67$ F 8 Hepamino

13.1 Normo-

blastic

B.S. 53 F 9 Hepamino

Meglovite oral
$\mathbf{B}_{12}$

12.7 Normo-

$38 \quad 104$

$\begin{array}{lll}6 & 7 \cdot 2 & 4 \cdot 0\end{array}$

$.5 \quad 4.0$

$\begin{array}{lllll}7 & 40.0 & 4.5 & 5.2 & 98\end{array}$

$31.0 \quad 50.0 \quad 40.0-$

$\begin{array}{lllll}\text { L.H. } & 68 & \mathrm{M} & 8 & \begin{array}{l}\text { Hepamino } \\ \text { Occasional } B_{1}\end{array}\end{array}$

14.5 Megaloid

$\begin{array}{lllllll}240 & 151 & 18.3 & 6.5 & 4.2 & 9.6 & 4.9\end{array}$

$\begin{array}{llll}21 \cdot 0 & 2 \cdot 2 & 6 \cdot 2 & 45\end{array}$

$\begin{array}{llll}28.0 & 61 \cdot 0 & 40.0 & 26.0\end{array}$ since 1957

J.F. 49 F 11 Hepamino

giant

$B_{12}$ since 1953

M.B. 43 F 8 Hepamino 195054 , folic and ora
$B_{12} 1954$, liver injections 1954-55

V.T. 51 F $7 \begin{aligned} & \text { Hepamino }+ \\ & \text { B }_{18} \text { tablets for }\end{aligned}$ a time

$15 \cdot 0$

12.5 Megaloid

giant

bands +

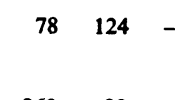

$\begin{array}{lllll}6.9 & 4.0 & 10.4 & 3.6 & 8\end{array}$

$\left.\left.\begin{array}{r}7 \cdot 0 \\ 10 \cdot 5\end{array}\right\} \begin{array}{l}1.89 \\ 2 \cdot 69\end{array}\right\} 7 \cdot 0$

$66 \quad 23 \cdot 0 \quad 33 \cdot 0 \quad-42 \cdot 0$

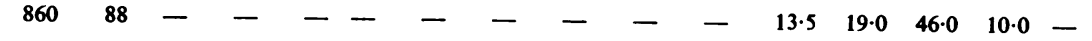

12.0 Megalo-

blastic

45

$\begin{array}{llll}46 & 19 \cdot 4 & 5 \cdot 5 & 2\end{array}$

$\begin{array}{lll}7.9 & 3.3\end{array}$

$\begin{array}{lll}10.8 & 1.8 & 4.7\end{array}$

$\begin{array}{lllll}7 & 5.0 & 29.0 & 44 \cdot 0 & 17 \cdot 0\end{array}$

$78 \quad 124$

$6 \quad 5.6$

$0 \quad 3.6$

Folic acid 1956- 10.4 Megalo-

$\begin{array}{llllllll}50 & 168 & - & 6.1 & 4.0 & 9.8 & 4.8 & 9\end{array}$

$11 \cdot 2-4.6$

$\begin{array}{lllll}79 & 24.0 & 33.0 & 44.0 & 27.0\end{array}$

A.B. $\left\{\begin{array}{lll}59 \quad M \quad 6 & \begin{array}{l}\text { Folic acid 1956- } \\ 57, \text { later proteo- } \\ \text { lysed liver }\end{array} \\ \begin{array}{l}\text { after 2nd } \\ \text { operation }\end{array} & \end{array}\right.$

blastic

14.4 Normo-

blastic

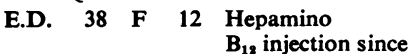

1952. A+D and

$\mathrm{Fe}$

G.W. 62 M 4 Hepamino

16.1 Normoblastic

$180--$

$\begin{array}{llllllll}1,300 & 110 & - & 6.6 & 4 \cdot 1 & 8.4 & 3 \cdot 1 & 17\end{array}$

$4 \cdot 5 \quad 1 \cdot 6$

$38 \quad 71$

$5.9 \quad 3 \cdot 6$

$9.4 \quad 3 \cdot 7$

5

$\begin{array}{llll}15 \cdot 2 & 2 \cdot 15 & 6 \cdot 8 & 76\end{array}$

6

$22.050 .0 \quad 2.53$

Subiects with oesophago-jejuno-gastrostomy

C.C. $43 \mathrm{M} 6$ None

16.6 Normo-

mths.

blastic

G. 42 F 5 Liver extract $\quad 14 \cdot 0$

Multiple vitamins

'Vagi not divided at operation

developed anaemia three to eight years following operation and were given liver injections, folic acid, or vitamin $\mathbf{B}_{12}$.

Other symptoms complained of were sore mouth and tongue in six, paraesthesiae in hands and feet in five, cramps in six, bone pain in three, which was accompanied by radiological evidence of osteoporosis in two, and oedema in two.

In spite of these disabilities they were all well pleased with the results of operation and were able to eat a reasonable diet. Most of them found it difficult to swallow much at any one time and regurgitated rather easily, but they emphasized that this was a minor disability compared with their miserable state before operation.

BLOOD COUNTS AND STERNAL MARROW Although five had been anaemic at some period since operation, 


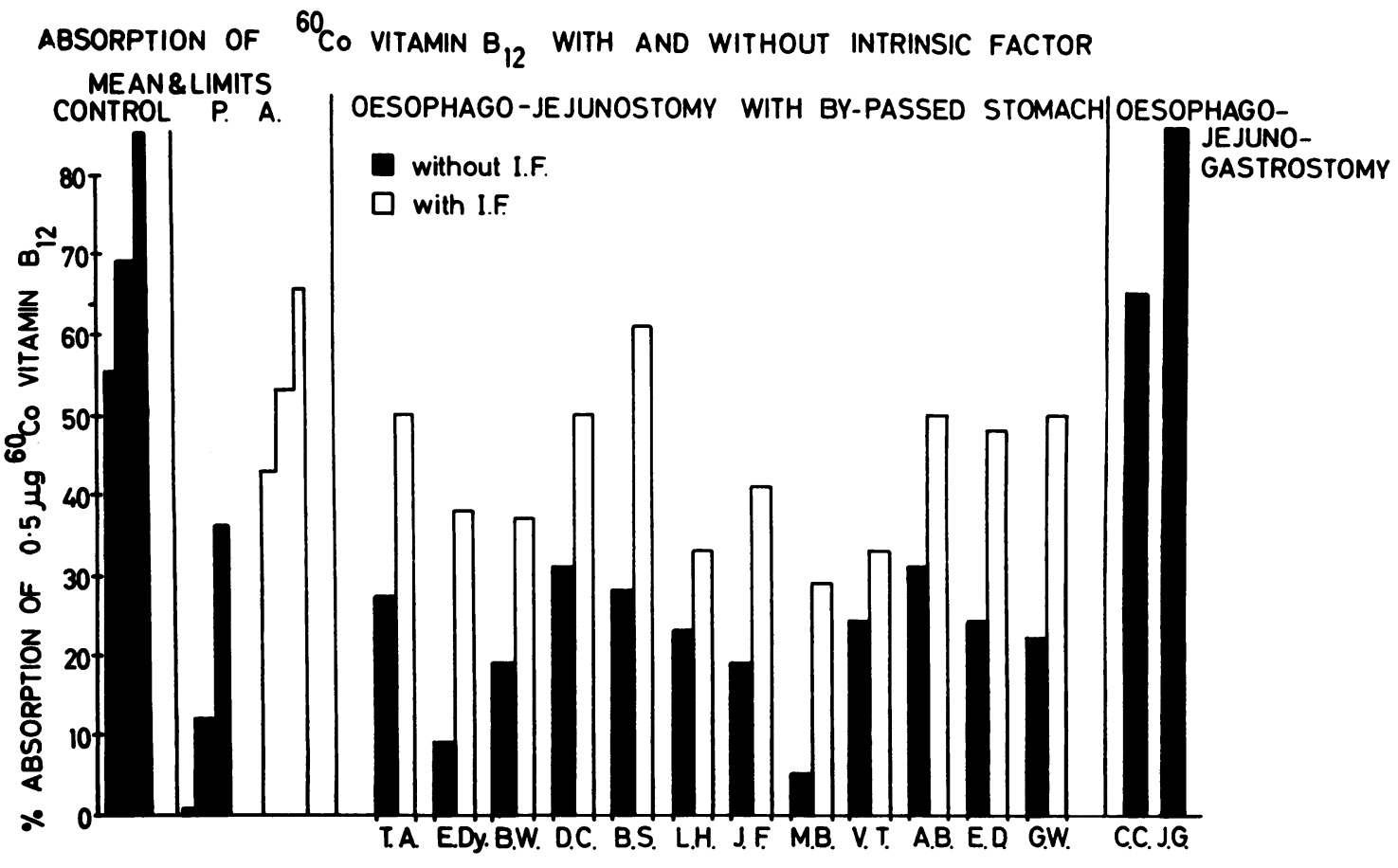

FIG. 2. Percentage absorption from an oral dose of $0.5 \mu \mathrm{g} .{ }^{60} \mathrm{Co}$ vitamin $B_{12}$ with and without intrinsic factor (I.F.) in 12 patients with oesophago-jejunostomy and by-passed stomach and two with oesophago-jejuno-gastrostomy.

in none was anaemia severe at the time of observation. The lowest haemoglobin was $10.4 \mathrm{~g}$. per $100 \mathrm{ml}$. Most of the values were within normal limits (Table I), although the majority of the blood films showed some macrocytosis. In two the bone marrow was megaloblastic, in four megaloid with many giant band forms, and in four normoblastic; one of these last four had been receiving parenteral vitamin $B_{12}$ and another oral vitamin $B_{12}$. In the remaining two the sternal marrow was not examined because they were on adequate maintenance therapy with vitamin $\mathbf{B}_{\mathbf{1 2}}$. Prothrombin time was slightly prolonged in three of the eight in whom it was tested.

SERUM VITAMIN $\mathbf{B}_{12}$ The level of serum vitamin $\mathbf{B}_{\mathbf{1 2}}$ was less than $100 \mu \mu \mathrm{g} . / \mathrm{ml}$. in all the patients except three who were receiving injections of vitamin $B_{12}$ and one who was taking oral tablets of vitamin $B_{12}$.

ABSORPTION OF ${ }^{60}$ CO-VITAMIN $B_{12}$ Absorption of radioactive vitamin $B_{12}$ was reduced in all the subjects. The values were all in the range for pernicious anaemia although the mean absorption for the group (22\%) was somewhat greater than the mean for pernicious anaemia (Fig. 2).

The addition of intrinsic factor enhanced absorption in all, although in two (V.T. and L.H.) there was only a $9 \%$ and $10 \%$ difference, respectively, which is doubtfully significant. In seven only of these patients was the preparation of intrinsic factor as effective in restoring the absorption towards normal as it was in subjects with pernicious anaemia.

Carbachol was given to five subjects in the test of absorption of vitamin $B_{12}$. In one, less of the vitamin was absorbed than without carbachol stimulation. In two the absorption was greater than that obtained with the addition of intrinsic factor and in the remaining two there was a doubtful enhancing effect.

Histamine stimulation was combined with a test of vitamin $B_{12}$ absorption in seven subjects. In four there was no difference between absorption with and without histamine stimulation; in the remaining three there was an increase in absorption similar to that obtained with intrinsic factor.

SERUM IRON In contrast to the reduced levels of serum $B_{12}$ the serum iron was within normal limits in all except three and in one only was it notably low $(27 \mu \mathrm{g} . / 100 \mathrm{ml}$.).

IRON ABSORPTION This was studied in five subjects. The percentage values for iron absorption were all below the mean of $25 \%$ of a $5-\mathrm{mg}$. dose of iron 
obtained in control non-anaemic subjects. In two in whom the serum iron was low (B.W. and V.T.) absorption was not as high as is usual in iron deficiency although it came within the control range.

FAT AND NITROGEN EXCRETION These were studied in 10 of the 12 patients. Steatorrhoea was a feature in all except one. The exception (E.D.) had been observed to have steatorrhoea when studied in another hospital in 1952, at which time she had been started on parenteral vitamin $B_{12}$.

The amount of fat excreted a day varied from 4.5 to $40 \mathrm{~g}$. with a mean of $14.5 \mathrm{~g}$. in 24 hours. Nitrogen excretion exceeded $2 \mathrm{~g}$. a day in four subjects.

It was noteworthy that the patient showing the grossest degree of steatorrhoea and negative nitrogen balance was the only one in whom special care had been taken not to divide the vagi at operation.

UROPEPSINOGEN EXCRETION Seven of the 12 subjects excreted less than 50 units of uropepsinogen in 24 hours. The remaining five showed normal excretion of uropepsinogen.

XYLOSE ABSORPTION TEST This indicated normal absorption of xylose in the eight subjects tested.

BLOOD CHEMISTRY The total plasma proteins were less than $6.5 \mathrm{~g}$. per $100 \mathrm{ml}$. in five of the subjects, in three they were under $6 \mathrm{~g}$. per $100 \mathrm{ml}$. In all, the albumin fraction was less than $4.4 \mathrm{~g}$. per $100 \mathrm{ml}$. and in eight it was $4 \mathrm{~g}$. per $100 \mathrm{ml}$. or less.

Serum calcium was reduced to $9 \mathrm{mg}$. $/ 100 \mathrm{ml}$. or less in seven subjects but this was certainly at least in part due to the hypoproteinaemia. The alkaline phosphatase was slightly increased in three subjects.

HISTOLOGY In six subjects biopsy of the jejunum was taken through the oesophagoscope. Five were normal. The sixth (E.Dy) showed loss of villi and a jejunitis comparable with that seen in idiopathic steatorrhoea.

Three subjects had sufficient symptoms and discomfort to warrant re-operation in order to put the stomach back into continuity with the gastrointestinal tract, and to convert the condition to an oesophago-jejuno-gastrostomy. The first (A.B.) was found at operation to have a small portion of the stomach intact (about $6 \mathrm{~cm}$. in length). Part of the cardia had been removed at the original operation. Biopsy of the remnant showed a completely normal mucosa (Fig. 3). Jejunal biopsy, however, showed some mild chronic inflammatory change and some pigmentation with lipofuchsin in the muscularis mucosae.

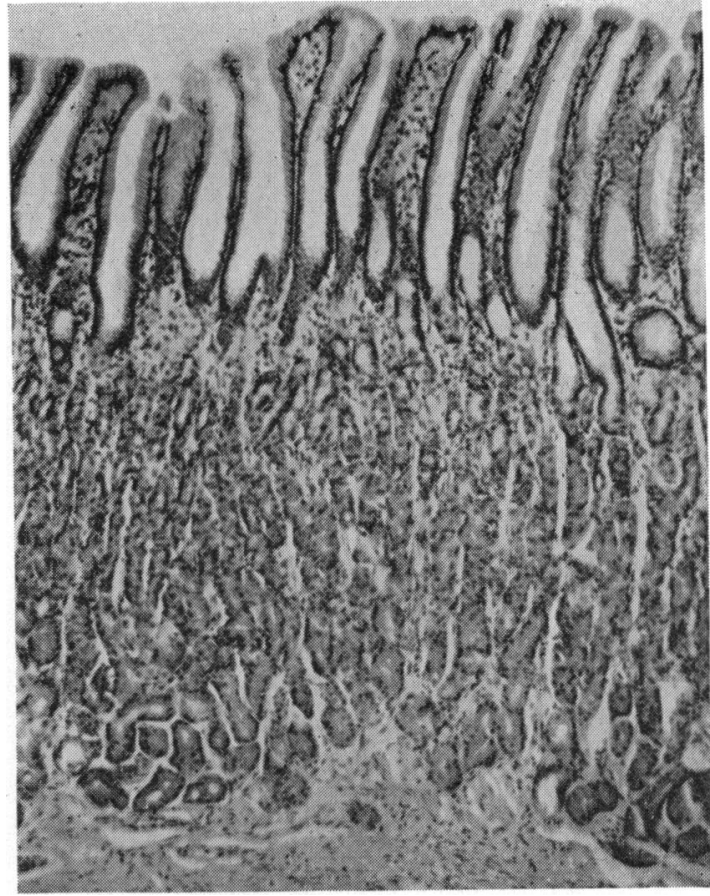

FIG. 3 Histology of gastric mucosa (patient A.B.) six years after the original by-pass operation.

The second and third patients (E.D. and G.W.) showed a superficial gastritis with preservation of the normal glandular tissue but normal histology of the jejunum.

RESULTS OF RE-OPERATION A.B. received no treatment with vitamin $B_{12}$ after operation but he improved clinically and put on weight. When seen six months later his serum $B_{12}$ was $180 \mu \mu \mathrm{g} . / \mathrm{ml}$. and his count was normal. A single test of absorption of labelled vitamin $B_{12}$ did not, however, reveal any improvement in absorption. It would clearly be desirable to repeat this test. Attempts to obtain gastric juice after operation were unsuccessful. The second patient (G.W.) was unfortunately found to have a bronchial neoplasm which was removed at the time of his re-operation. He was never sufficiently well to be submitted to any adequate post-operative studies.

The third patient (E.D) was studied more fully. Nine days after the operation the absorption of labelled $B_{12}$ had improved from 24 to $42 \%$, i.e., to a value comparable to that found previously with the addition of intrinsic factor. A sample of this patient's gastric juice obtained through a gastrostomy a few days after operation was acid, and $100 \mathrm{ml}$. of the juice improved the absorption of ${ }^{60} \mathrm{Co}$-vitamin 
$B_{12}$ in a patient with pernicious anaemia from 12 to $78 \%$, indicating that it contained active intrinsic factor.

\section{RESULTS IN PATIENTS WITH OESOPHAGO- JEJUNO-GASTROSTOMY}

Two patients (J.G. and C.C.) were studied five years and six months respectively after the operation of oesophago-jejuno-gastrostomy. Both had had severe symptoms dating back to infancy, necessitating feeding by gastrostomy for periods of years, and many attempts to relieve their peptic stricture of the oesophagus by dilatation or less drastic surgical procedure. The operation of oesophago-jejunogastrostomy was of great benefit to both.

Like the first group they both suffered from diarrhoea after operation although one only (J.G.) had it severely. The diarrhoea gradually settled after a year, but this patient lost about $7 \mathrm{~kg}$. of weight, this being her main post-operative complaint. She had treated herself with multiple vitamin preparations plus calcium and liver extract since operation. The other patient had no specific therapy.

Blood counts and bone marrow of both these patients were normal. The subject who had been having injections of liver extract had a serum $B_{12}$ of $1,500 \mu \mu \mathrm{g} . / \mathrm{ml}$., in the other it was $160 \mu \mu \mathrm{g} . / \mathrm{ml}$. In contrast to the patients with a by-passed stomach, absorption of ${ }^{60} \mathrm{Co}$-vitamin $\mathrm{B}_{12}$ was normal in both.

There was a borderline steatorrhoea in both, the plasma proteins were low in one, probably reflecting his long period of malnutrition before operation; in the other the proteins were normal but the serum calcium was reduced.

Uropepsinogen excretion was measured in one only and it was reduced.

A biopsy was taken from the jejunal loop through an oesophagoscope and in both subjects the appearance of the mucosa was normal.

\section{DISCUSSION}

The patients were seen in the course of a review of the results of oesophago-jejunostomy with by-pass of the stomach for oesophageal stricture. They had received a variable amount of antianaemic treatment and it would not have been practicable to impose a control period without therapy, even had this been justifiable on other grounds. The surprising thing is that the majority of the patients nevertheless showed a condition which could most simply be described as a latent or subclinical pernicious anaemia. The level of vitamin $B_{12}$ in the serum was in the pernicious anaemia range except for three patients who were receiving injections of vitamin $B_{12}$ and one who was taking oral tablets of vitamin $B_{12}$. The blood films were mostly macrocytic and the marrow films were megaloblastic or megaloid in the majority of cases. Absorption of radioactive vitamin $\mathbf{B}_{12}$ was reduced in all cases to the levels found in pernicious anaemia and in all it was improved by the simultaneous administration of intrinsic factor, although not always as effectively as in pernicious anaemia.

The reason for the development of vitamin $B_{12}$ deficiency is not at all clear. It does not seem to have been due to defective intestinal absorption. Although steatorrhoea was present, often in considerable degree, intrinsic factor was effective in enhancing absorption of vitamin $\mathbf{B}_{12}$. Xylose was absorbed normally and jejunal biopsy usually gave normal results.

The low level of uropepsinogen excretion in more than half the patients might suggest that the bypassed stomach was inactive and failed to secrete intrinsic factor. Clearly, the gastric phase of gastric secretion should have been abolished by the operation. The psychic secretion was abolished or diminished because the vagi were usually densely bound up in the peri-oesophagitis associated with the stricture and therefore were almost certainly divided at operation. Nevertheless, in one case it was believed that the vagi were in part preserved. The intestinal phase of gastric secretion was likely to have been reduced by the side-tracking of the duodenum though some regurgitation of food into the duodenum may occur in these cases. However, it would seem probable from the work of Johnston and Welbourn (1958) and Plzak, Price, and Woodward (1958), who have carried out an identical operation in dogs, that gastric juice is secreted and enters the intestine in these cases.

Quite small amounts of intrinsic factor are probably sufficient to prevent pernicious anaemia, as shown by the rarity of its occurrence after partial gastrectomy and its absence in more than half the cases of complete achlorhydria (Callender, Retief, and Witts, 1960). The histology of the gastric mucosa was normal or near normal in the three cases where it was possible to examine it, and in one of them the gastric juice was shown to contain intrinsic factor after restoration of the continuity of the stomach with the gastrointestinal tract. Finally, there is the fact that stimulation of the by-passed stomach by carbachol and histamine was not always effective in increasing absorption of vitamin $\mathbf{B}_{12}$. Suppression of gastric secretion is therefore unlikely to be the main explanation of the development of vitamin $\mathbf{B}_{\mathbf{1 2}}$ deficiency in these patients, although it may play some part.

It would seem more likely that the normal conditions for the complexing of vitamin $\mathbf{B}_{12}$ and 
intrinsic factor before absorption are not satisfied when the intrinsic factor is not delivered until some little way down the jejunum instead of in the stomach. In these circumstances vitamin $B_{12}$ may become bound to substances which prevent its union with intrinsic factor, or intrinsic factor may be inactivated before it meets the vitamin $B_{12}$. Unfortunately, no experiments were carried out in which the tracer dose of radioactive vitamin $B_{12}$ was given together with a vitamin $B_{12}$-free meal. It has recently been shown in this laboratory that after partial gastrectomy radioactive vitamin $B_{12}$ is absorbed better when given with food than when given alone, and similar conditions might prevail in these patients with bypassed stomachs (Deller, Germor, and Witts, 1961).

In contrast to the frequency of vitamin $B_{12}$ deficiency in these cases is the rarity of iron deficiency. The absorption of iron was impaired, but not to the degree seen in idiopathic steatorrhoea. Only three of the patients were women who were still menstruating so that the demands for iron were not great. In view of the considerable degree of steatorrhoea it is not surprising that serum calcium levels tended to be low though serum phosphorus and phosphatase levels were normal. Serum albumin also tended to be low but the falls in calcium and albumin were not closely correlated. Osteomalacia was not seen but osteoporosis occurred in two women. Although in one this may have been only an aggravation of the common tendency to osteoporosis seen after the menopause, the other (E.D.) was the youngest woman in the series and the osteoporosis appeared to be attributable solely to the operation. She developed anaemia and gross steatorrhoea, both of which appeared to improve on parenteral vitamin $B_{12}$ therapy.

The observations on the two subjects with oesophago-jejuno-gastrostomy indicate the superiority of this operation in that the absorption of vitamin $B_{12}$ was normal, and there was little if any steatorrhoea.

\section{SUMMARY}

Twelve subjects in whom the operation of oesophagojejunostomy was performed, leaving the stomach in situ, were studied four to 12 years after the operation.
All showed considerable metabolic disturbance, the main feature being steatorrhoea and inability to absorb vitamin $\mathbf{B}_{\mathbf{1 2}}$.

Gastric secretion may be suppressed but the more likely explanation of the poor absorption of vitamin $B_{12}$ is disturbance of the normal conditions for the complexing of vitamin $B_{12}$ and intrinsic factor.

The operation has now been abandoned in favour of oesophago-jejuno-gastrostomy. Two patients in whom this operation had been performed showed normal absorption of vitamin $B_{12}$.

We are indebted to Dr. G. H. Spray for estimations of vitamin $\mathbf{B}_{12}$ in the serum, Mr. J. R. P. O'Brien for some of the biochemical estimations, Dr. W. C. D. Richards for histological reports, and Miss B. M. Mallett and Mr. S. W. Perry for technical assistance. The work was in part aided by a grant to Professor L. J. Witts from the Medical Research Council.

\section{REFERENCES}

Aitken, M. A., Spray, G. H., and Walters, G. (1954). Gastric pepsin and the excretion of uropepsinogen in anaemia. Clin. Sci., 13, 119-126.

Anson, M. L. (1938). The estimation of pepsin, typsin, papain, and cathepsin with hemoglobin. J. gen. Physiol., 22, 79-89.

Bradley, J. E. (1957). Quoted by Mollin, D. L., Booth, C. C., and Baker, S. J. Brit. J. Haemat., 3, 412-428.

Callender, S. T., Mallett, B. J., and Smith, M. D. (1957). Absorption of haemoglobin iron. Ibid, 3, 186-192.

- Retief, F. P., and Witts, L. J. (1960). The augmented histamine test with special reference to achlorhydria. Gut, 1, 326-336.

- Turnbull, A., and Wakisaka, G. (1954). Estimation of intrinsic factor of Castle by use of radioactive vitamin $B_{12}$. Brit. med. J., 1, 10-12.

Deller, D. J., Germor, H., and Witts, L. J. (1961). Effect of food on absorption of radioactive vitamin $B_{12}$. Lancet, 1, 574-577.

Johnston, I. D. A., and Welbourn, R. B. (1958). The influence of the secretory function of the stomach on nutrition in the dog. Brit. J. Surg., 46, 163-169.

Kamer, J. H. van de, Bokkel Huinink, H. ten, and Weyers, H. A. (1949). Rapid method for the determination of fat in feces. J. biol. Chem., 177, 347-355.

Perry, S. (1960). Unpublished data.

Plzak, L., Price, L., and Woodward, E. R. (1958). The effect of complete exclusion of the stomach on fat and nitrogen absorption. Surgery, 44, 299-392.

Retief, F. P. (1959). A study of achlorhydria and its relation to anaemia. Thesis submitted for D. Phil., Oxon.

Spray, G. H. (1955). An improved method for the rapid estimation of vitamin $B_{12}$ in serum. Clin. Sci., 14, 661-667.

— and Witts, L. J. (1958). Results of three years' experience with microbiological assay of vitamin $B_{1 z}$ in serum. Brit. med. J., 1, 295-298. 